\title{
Haloperidol Loaded Solid Lipid Nanoparticles for Nose to Brain Delivery: Stability and In vivo Studies
}

\section{Mohd Yasir ${ }^{1,2 *}$, UVS Sara ${ }^{3}$ and Iti Som ${ }^{2}$}

${ }^{1}$ Department of Pharmacy, Uttarakhand Technical University, Dehradun-248007, Uttarakhand, India

${ }^{2}$ Department of Pharmaceutics, ITS College of Pharmacy, Ghaziabad, Uttar Pradesh, India

${ }^{3}$ Department of Pharmaceutics, Dr. M C Saxena College of Pharmacy, Lucknow-226101, Uttar Pradesh, India

\begin{abstract}
In the present study, Haloperidol loaded solid lipid nanoparticles were prepared to enhance its uptake to brain via intranasal route. SLNs were prepared by modified emulsification diffusion technique. For optimization, a three factors and three levels Box - Behnken design was applied to study the effect of independent variables (factors) i.e. drug to lipid ratio $(A)$, surfactant concentration $(B)$ and stirring speed $(C)$ on dependent variables (responses) i.e. particles size (Y1), entrapment efficiency (Y2), and drug loading (Y3). The value of optimized variables for HP-SLNs was 1:2 (drug to lipid ratio), $1.625 \%$ (surfactant concentration) and $3000 \mathrm{rpm}$ (stirring speed). The optimized HP-SLNs formulation was evaluated for stability and in vivo studies. Stability studies revealed no significant $(P<0.5)$ change was observed in particle size, zeta potential, entrapment efficiency and drug loading of optimized HP-SLNs formulation when it was stored at $4 \pm 2^{\circ} \mathrm{C}$ (refrigerator) and $25 \pm 2^{\circ} \mathrm{C} / 60 \pm 5 \% \mathrm{RH}$ up to six months, but the size of particles was increased significantly $(\mathrm{P}<0.001)$ when the optimized formulation was stored at $40 \pm 2^{\circ} \mathrm{C} / 75 \pm 5 \% \mathrm{RH}$. A significant drop $(\mathrm{P}<0.001)$ in zeta potential was also observed at $40 \pm 2^{\circ} \mathrm{C} / 75 \pm 5 \% \mathrm{RH}$ after 3 months. In vivo studies were performed on albino Wistar rats and various pharmacokinetic and brain targeting parameters were determined. The pharmacokinetic parameters in brain after i.n. administration of HP-SLNs were found to be, $\mathrm{T}_{\max } 2 \mathrm{~h}, \mathrm{C}_{\max } 329.17 \pm 20.89 \mathrm{ng} / \mathrm{mL}, \mathrm{AUC0}$ $-\infty 2389.17 \pm 78.82 \mathrm{ng} . \mathrm{h} / \mathrm{mL}$, Ke $0.079 \pm 0.0065 \mathrm{~h}^{-1}$ and MRT $12.60 \pm 0.99 \mathrm{~h}$.
\end{abstract}

The value of brain targeting parameters like drug targeting index, drug targeting efficiency and nose to brain direct transport were found to be $23.62,2362.43 \%$ and $95.77 \%$ and $11.28,1128.61 \%$ and $91.14 \%$ for HP-SLNs i.n. and HP Sol i.n. respectively.

Keywords: Brain targeting; Haloperidol; Intranasal; Pharmacokinetic; Stability; Solid lipid nanoparticles

Abbreviations: $\mathrm{AUC}_{0-\infty}$ : Area under the Curve from Time 0 to Time Infinity; $\mathrm{AUC}_{0-\mathrm{T}}$ : Area under the Curve from Time 0 to Time T; BBB: Blood Brain Barrier; $\mathrm{C}_{\max }$ : Peak of Maximum Concentration; DTE: Drug Targeting Efficiency; DTI: Drug Targeting Index; DTP: Direct Transport Percentage; I.N: Intranasal; I.V.: Intravenous; RB: Relative Bioavailability; RSM: Response Surface Methodology; SD: Standard Deviation; SLNs: Solid Lipid Nanoparticles

\section{Introduction}

Nanoparticles are one of the novel colloidal drug delivery systems that hold great promise for reaching the goal of site specific delivery as well as controlled drug delivery [1]. One area in which nanoparticles may have a significant clinical impact is neuroscience where they can help to transport and deliver the drug molecules across the blood brain barrier (BBB) that cannot cross otherwise [2]. Drug molecules are required to cross $\mathrm{BBB}$ to reach the brain. Most of the drug molecule either fails to cross the BBB due to their poor penetration or due to the efflux mechanism of the brain [3]. To overcome these problems, various nanoparticle based drug delivery systems have been designed by different researchers. Here a considerable attention has been paid to Solid Lipid Nanoparticles (SLNs) as possible drug carrier to overcome the BBB [4]. SLNs represent an alternative carrier to traditional colloidal carriers due to their higher drug loading capacity, lower cytotoxicity, controlled as well as site specific drug targeting and excellent production scalability. They are made up of physiological lipids resulting good biocompatibility [5].

The route chosen for delivering SLNs was intranasal. This route is useful and reliable alternative to oral and parenteral routes. It reduces the systemic exposure and thus systemic side effects of drug. Improved bioavailability of drug candidates that undergo the hepatic first pass metabolism was also observed.

Haloperidol (HP) was selected as a dug candidate. It is a dopamine inverse agonist of the typical antipsychotic class of medications that chemically belongs to butyrophenone group [6,7]. Its mechanism of action is mediated by blockade of D2 dopamine receptors in brain $[8,9]$. It is used to treat certain psychiatric conditions including schizophrenia, maniac states, medicament induced psychosis and neurological disorders with hyperkinesias. After oral drug delivery, the drug undergoes first pass metabolism and gets distributed systemically resulting a small portion being able to reach the brain through the blood. The plasma protein binding of haloperidol is about $90 \%$, thereby further affecting its oral bioavailability. Specific clinical complications associated with a high systemic concentration include respiratory disturbance (bronchospasm and increased depth of respiration), dermatological reactions (maculopapular and acneiform skin reactions), nausea, vomiting and musculoskeletal disorder [10].

For the drug to be a good candidate for brain targeting upon intranasal administration it must have following characteristics:

*Corresponding author: Mohd Yasir, Department of Pharmaceutics, ITS College of Pharmacy, Muradnagar, Ghaziabad - 201206, Uttar Pradesh, India, Tel: 919761131206; Fax: (01232) 225380; E-mail: mohdyasir31@gmail.com

Received December 01, 2015; Accepted December 21, 2015; Published December 31, 2015

Citation: Yasir M, Sara UVS, Som I (2015) Haloperidol Loaded Solid Lipid Nanoparticles for Nose to Brain Delivery: Stability and In vivo Studies. J Nanomedic Nanotechnol S7:006. doi:10.4172/2157-7439.S7-006

Copyright: ( 2015 Yasir M, et al. This is an open-access article distributed under the terms of the Creative Commons Attribution License, which permits unrestricted use, distribution, and reproduction in any medium, provided the original author and source are credited. 
Citation: Yasir M, Sara UVS, Som I (2015) Haloperidol Loaded Solid Lipid Nanoparticles for Nose to Brain Delivery: Stability and In vivo Studies. J Nanomedic Nanotechnol S7:006. doi:10.4172/2157-7439.S7-006

Page 2 of 9

a) The drug should have favourable oil and water partition coefficient

b) Molecular weight $<500 \mathrm{D}$

c) Small dose of drug

Haloperidol posses all three characteristics as the $\log \mathrm{P}$ value of haloperidol is 3.36 [6], molecular weight of $375.86 \mathrm{~g} / \mathrm{mol} \mathrm{[11]} \mathrm{and}$ maintenance dose is $10 \mathrm{mg} /$ day [12].

\section{Materials and Methods}

\section{Materials}

Haloperidol was received as a gift sample from Vamsi Labs Ltd. (Solapur, Maharashtra, India). Glyceryl monostearate (GMS) was obtained as a gift sample from Gattefosse (Witten, Germany). Acetonitrile (ACN), triethylamine (TEA), o - phosphoric acid (o - PA) and tween 80 along with all the other chemicals were purchased from Sigma-Aldrich (New Delhi, India). Potassium dihydrogen phosphate was purchased from Qualigens fine chemicals, Mumbai (India), and Sodium hydroxide was purchased from Fisher scientific, Mumbai (India). ACN, TEA, o - PA were HPLC grade while all other solvents and chemicals used were of analytical grade. Water was distilled and filtered before use through a $0.22 \mu \mathrm{m}$ membrane filter.

\section{Preparation of SLNs}

Haloperidol loaded SLNs (HP-SLNs) were prepared by previously reported solvent emulsification-diffusion technique $[7,13]$. Lipid was dissolved in a mixture of ethanol and chloroform as the internal oil phase. Drug was dispersed in the above solution. This organic phase was then poured drop by drop into a homogenizer tube containing aqueous solution of tween 80 , as the external aqueous phase and homogenized for $30 \mathrm{~min}$ to form primary emulsion $(\mathrm{o} / \mathrm{w})$. The above emulsion was poured into $75 \mathrm{ml}$ of ice-cold water $\left(2-3^{\circ} \mathrm{C}\right)$ containing surfactant and stirred to extract the organic solvent into the continuous phase and for proper solidification of SLNs. The stirring was continued followed by sonication to get SLN dispersion of uniform size. The SLN dispersion was lyophilized by adding mannitol to get lyophilized SLNs.

To optimize the production of SLNs, a statistically experimental design methodology (Box-Behnken design) was employed [14]. 3 critical independent variables like drug to lipid ratio (A), surfactant concentration (B) and stirring speed (C) were selected on the basis of results of pre-optimization studies (Table 1). The effect of these 3 independent variables was observed on particle size (Y1), entrapment efficiency (\%Y2), and drug loading (\%Y3). The response surface methodology of the Box-Behnken design (version 8.0.7.1, Stat-Ease, Inc., Minneapolis, Minnesota, USA), using a three-factors, threelevels, was employed to optimize dependent variables like particle size (Y1), entrapment efficiency (Y2), and drug loading (Y3) variables. For 3 factors- three levels, it gives total 17 runs as shown in Table 2.

\begin{tabular}{|l|c|c|c|}
\hline Variables & \multicolumn{3}{|c|}{ Level of variables } \\
\hline Independent variables & Low $(-1)$ & Medium $(0)$ & High $(+1)$ \\
\hline A = Drug to lipid ratio & $1: 2$ & $1: 3$ & $1: 4$ \\
\hline $\mathrm{B}=$ Surfactant (\%) & 1 & 1.5 & 2 \\
\hline $\mathrm{C}=$ Stirring speed (RPM) & 2000 & 2500 & 3000 \\
\hline Dependent variables & \multicolumn{3}{|c}{ Goals } \\
\hline Y1 = Particles size & Minimize \\
\hline Y2 = $\%$ D & Maximize \\
\hline Y3 = $\%$ L & & Maximize \\
\hline
\end{tabular}

Table 1: Variables and their levels in Box-Behnken design.

\begin{tabular}{|c|c|c|c|c|c|c|}
\hline \multirow{2}{*}{$\begin{array}{l}\text { Formulation } \\
\text { code }\end{array}$} & \multicolumn{3}{|c|}{ Coded value } & \multicolumn{3}{|c|}{ Actual value } \\
\hline & A & B & C & $\begin{array}{l}\text { Drug to } \\
\text { lipid ratio }\end{array}$ & $\begin{array}{c}\text { Surfactant } \\
\text { Conc. (\%) }\end{array}$ & $\begin{array}{c}\text { Stirring speed } \\
(\mathrm{rpm})\end{array}$ \\
\hline $\mathrm{H} 1$ & -1 & -1 & 0 & $1: 2$ & 1 & 2500 \\
\hline $\mathrm{H} 2$ & 1 & -1 & 0 & $1: 4$ & 1 & 2500 \\
\hline $\mathrm{H} 3$ & -1 & 1 & 0 & $1: 2$ & 2 & 2500 \\
\hline $\mathrm{H} 4$ & 1 & 1 & 0 & $1: 4$ & 2 & 2500 \\
\hline H5 & -1 & 0 & -1 & $1: 2$ & 1.5 & 2000 \\
\hline $\mathrm{H} 6$ & 1 & 0 & -1 & $1: 4$ & 1.5 & 2000 \\
\hline $\mathrm{H} 7$ & -1 & 0 & 1 & $1: 2$ & 1.5 & 3000 \\
\hline $\mathrm{H} 8$ & 1 & 0 & 1 & $1: 4$ & 1.5 & 3000 \\
\hline H9 & 0 & -1 & -1 & $1: 3$ & 1 & 2000 \\
\hline $\mathrm{H} 10$ & 0 & 1 & -1 & $1: 3$ & 2 & 2000 \\
\hline $\mathrm{H} 11$ & 0 & -1 & 1 & $1: 3$ & 1 & 3000 \\
\hline $\mathrm{H} 12$ & 0 & 1 & 1 & $1: 3$ & 2 & 3000 \\
\hline $\mathrm{H} 13$ & 0 & 0 & 0 & $1: 3$ & 1.5 & 2500 \\
\hline $\mathrm{H} 14$ & 0 & 0 & 0 & $1: 3$ & 1.5 & 2500 \\
\hline $\mathrm{H} 15$ & 0 & 0 & 0 & $1: 3$ & 1.5 & 2500 \\
\hline $\mathrm{H} 16$ & 0 & 0 & 0 & $1: 3$ & 1.5 & 2500 \\
\hline $\mathrm{H} 17$ & 0 & 0 & 0 & $1: 3$ & 1.5 & 2500 \\
\hline
\end{tabular}

Optimization of data and validation of response surface methodology

Different batches (H1-H17) were prepared with different independent variables at different levels and responses like particle size, entrapment efficiency and drug loading were obtained. The data was substituted to design expert software; polynomial equations were generated and optimized on basis of ANOVA in the software. The models were evaluated in terms of statistically significant coefficients and $\mathrm{R}^{2}$ values. Contour plots were used to assess the relationship between the variables and responses. The criterion for selection of optimum formulations was based on the highest possible value of entrapment efficiency (Y2), and drug loading (Y3) and smallest value of particle size (Y3). Finally, four optimized formulations (H7 OH1, $\mathrm{OH} 2$ and $\mathrm{OH} 3$ ) were selected as check point to validate RSM (Table 3 ). These formulations were again prepared and evaluated for responses. The resulting observed responses were compared with the predicted responses and percent error was calculated. Linear regression plots between actual and predicted responses were plotted [15].

\section{Stability studies}

The optimized HP - SLNs (OPH) formulation was subjected to stability studies and the studies were performed in triplicate. The storage conditions for stability testing were $4 \pm 2^{\circ} \mathrm{C}$ (refrigerator), 25 $\pm 2^{\circ} \mathrm{C} / 60 \pm 5 \% \mathrm{RH}$, and $40 \pm 2^{\circ} \mathrm{C} / 75 \pm 5 \%$ in stability chamber (Hicon instruments, N. Delhi). The sample was withdrawn after a period of $0,1,3$ and 6 months and the effect on particle size, zeta potential, entrapment efficiency and loading capacity was determined. These parameters were analysed for statistical significance by one way analysis of variance (ANOVA) followed by Dunnett's multiple comparison test using GraphPad Instat software (GraphPad Software Inc., CA, USA). Results at zero time study were taken as control.

\section{In vivo Studies for the determination of pharmacokinetic and brain targeting parameters}

In vivo studies were performed on male albino Wistar rats (Adult/ weighing 200-250 g). A protocol for animal studies was approved by 
Citation: Yasir M, Sara UVS, Som I (2015) Haloperidol Loaded Solid Lipid Nanoparticles for Nose to Brain Delivery: Stability and In vivo Studies. J Nanomedic Nanotechnol S7:006. doi:10.4172/2157-7439.S7-006

Page 3 of 9

\begin{tabular}{|c|c|c|c|c|c|c|}
\hline \multirow[t]{2}{*}{ FC } & \multicolumn{3}{|c|}{ Coded value } & \multicolumn{3}{|c|}{ Actual value } \\
\hline & A & B & C & Drug to lipid ratio & $\begin{array}{l}\text { Surfactant } \\
\text { Conc. (\%) }\end{array}$ & Stirring speed (rpm) \\
\hline $\mathrm{H} 7$ & -1 & 00 & 1 & $1: 2$ & 1.5 & 3000 \\
\hline $\mathrm{OH} 1$ & -0.75 & 00 & 1 & $1: 1.5$ & 1.5 & 3000 \\
\hline $\mathrm{OH} 2$ & -0.75 & 0.25 & 1 & $1: 1.5$ & 1.625 & 3000 \\
\hline $\mathrm{OH} 3$ & -1 & 0.25 & 1 & $1: 2$ & 1.65 & 3000 \\
\hline
\end{tabular}

FC=Formulation code

Table 3: Point prediction check point for optimization, coded and actual values of independent variables.

Institutional animal ethical committee and project number was 03 . The animals were kept under standard laboratory conditions, temperature of $22 \pm 3^{\circ} \mathrm{C}$ and relative humidity of $30 \%-70 \%$. The animals were housed in polypropylene cages, 6 animals per cage with free access to standard laboratory diet and water ad libitum.

Comparative in vivo studies were performed for both haloperidol solution (positive control) (HP-Sol) and HP-loaded SLNs administered intranasally (i.n.) and HP-Sol (positive control) administered intravenously (i.v.). For this purpose, Rats were divided in three different groups:

Group A, positive control for i.v. drug administration (HP-Sol);

Group B, positive control for i.n. drug administration (HP-Sol); and

Group C, i.n. formulation administration (HP - SLNs)

Each group was divided into 8 subgroups (containing 6 animals in each) on time basis as, $0.167 \mathrm{~h}, 0.5 \mathrm{~h}, 1 \mathrm{~h}, 2 \mathrm{~h}, 4 \mathrm{~h}, 6 \mathrm{~h}, 8 \mathrm{~h}$ and $24 \mathrm{~h}$.

\section{Procedure for drug administration and analysis}

Drug solution (positive control), containing $0.179 \mathrm{mg}$ (for rat weighing $200 \mathrm{~g}$ ) of haloperidol (equivalent to $0.89 \mathrm{mg} / \mathrm{kg}$ body weight), was injected through the tail vein $(10 \mu \mathrm{L})$ in one group of rats. Similarly, drug solution and drug formulation (HP-SLNs) containing 0.179 $\mathrm{mg}$ of haloperidol were administered in each nostril in the other two groups with the help of micropipette $(10-100 \mu \mathrm{L})$ with $0.1 \mathrm{~mm}$ internal diameter at the delivery site. The rats were anaesthetized prior to nasal administration by pentobarbital sodium $(35-50 \mathrm{mg} / \mathrm{kg}$, i.p.) and held firmly from the back in a slanted position during nasal administration. The rats were killed humanely by overdose of pentobarbital sodium at different time intervals $(0.167,0.5,1,2,4,6,8$ and $24 \mathrm{~h})$ and the blood was collected using cardiac puncture in EDTA coated Eppendrof tubes. The presence haloperidol in blood was analysed by using HPLC.

Plasma concentration-time profile of haloperidol after i.n. and i.v. delivery were evaluated by pharmacokinetic software (PK Functions for Microsoft Excel, Pharsight Corporation, Mountain View, CA, USA). Various pharmacokinetic parameters as $\mathrm{C}_{\max }, \mathrm{T}_{\max }, \mathrm{AUC}_{0-\mathrm{t}}, \mathrm{AUC}_{0-\infty}$, elimination rate constant (Ke) and mean residence time (MRT) were calculated. Statistical analysis was performed using Graph pad prism 5.0 (Graph pad software San Diego, CA). All results are expressed as mean \pm SD. Difference among the groups was compared with the analysis of variance (ANOVA) followed by Tukey-Kramer multiple comparison tests. P - Value $<0.05$ was considered statistically significant. The extent of nose-to brain delivery was evaluated by following parameters [16]. These parameters are:

1. The brain/blood ratio, at $0.5 \mathrm{~h}$, following intranasal and intravenous administrations

2. The relative bioavailability (RB) percentages following the intranasal administration in the blood and brain. The relative bioavailability (\%) of the intranasal HP-SLNs formulation to intranasal HP-Sol. was determined according to following equation (1).

$$
\operatorname{RB}(\%)=\frac{\left(\mathrm{AUC}_{\mathrm{HP}-\mathrm{SLN}(0-\infty)}\right) \text { i.n. }}{\left(\mathrm{AUC}_{\mathrm{HPsol}(0-\infty)}\right) \text { i.n. }} \times 100
$$

3. The drug targeting index (DTI) [17]. The DTI can be described as the ratio of the AUC brain/AUC blood following i.n. administration to that following i.v. administration. Following equation (2) was used for the determination of DTI.

$$
\text { DTI }=\frac{\text { (AUC brain/AUC blood)i.n. }}{\text { (AUC brain/AUC blood)i.v. }}
$$

4. The drug targeting efficiency (DTE) percentage and the nose-to-brain direct transport percentage (DTP) [17]. The percent brain targeting efficiency (DTE\%) and nose to brain direct transport percentage (DTP\%) were calculated with the help of given equation (3 and 4$)$.

$$
\begin{aligned}
& \operatorname{DTE}(\%)=\frac{\left(\mathrm{AUC}_{\text {brain }} / \mathrm{AUC}_{\text {blood }}\right)_{0-24, \text { i.n. }}}{\left(\mathrm{AUC}_{\text {brain }} / \mathrm{AUC}_{\text {blood }}\right)_{0-24, \text { i.v. }}} \times 100 \\
& \operatorname{DTP}(\%)=\frac{\left(\mathrm{AUC}_{0-24, \text { brain,i.n. }}-F\right)}{\left(\mathrm{AUC}_{0-24, \text { brain, i.n. }}\right)} \times 100
\end{aligned}
$$

where $F=\left(\mathrm{AUC}_{0-24, \text { brain, i.v. }} / \mathrm{AUC}_{0-24 \text {, blood, iv. }}\right) \times \mathrm{AUC}_{0-24 \text {, blood, i.n. }}, \mathrm{AUC}_{0-24}$ brain, in is the area under the curve of brain following i.n. administration, AUC $_{0-24, \text { brain, i.v. }}$ is the area under the curve of brain following i.v. administration, $\mathrm{AUC}_{0-24 \text { blood, i.v. }}$ is the area under the curve of blood following i.v. administration, $\mathrm{AUC}_{0-24 \text { blood, i.n. }}$ is the area under the curve of blood following i.n. administration.

\section{Result and Discussion}

On the bases of results obtained in the preliminary optimization studies, three levels of each independent variable (factors) were decided. For three factors, the Box-Behnken design was chosen. On applying three factors and three levels Box-Behnken statistical design, 17 runs with five centre points were obtained. All these batches were prepared by solvent emulsification - diffusion technique and evaluated for responses like particles size (Y1), \% drug entrapment efficiency (Y2) and \% drug loading (Y3). All the results were placed in Box Behnken design of Design Expert software (version 8.0.7.1). All individual and interactive effects of these process variables were studied and all the responses fitted to first order, second order and quadratic models. Among the different models, the quadratic model was found to be the best fitted $(p<0.0001)$ for all responses (Table 4$)$. Analysis of variance of calculated model for responses is depicted in Table 5.

\section{Effect of independent factors on particle size}

The second-order polynomial equation (5) relating the response of particle size (Y1) is given below: 
Citation: Yasir M, Sara UVS, Som I (2015) Haloperidol Loaded Solid Lipid Nanoparticles for Nose to Brain Delivery: Stability and In vivo Studies. J Nanomedic Nanotechnol S7:006. doi:10.4172/2157-7439.S7-006

Page 4 of 9

\begin{tabular}{|c|c|c|c|c|c|c|}
\hline Model & $\mathbf{R}^{2}$ & Adjusted $\mathrm{R}^{2}$ & Predicted R2 & SD & $\% \mathrm{CV}$ & Remark \\
\hline \multicolumn{7}{|c|}{ Response (Y1) } \\
\hline Linear & 0.5819 & 0.4854 & 0.2227 & 26.77 & - & - \\
\hline $2 \mathrm{FI}$ & 0.6421 & 0.4274 & -0.4315 & 28.24 & - & - \\
\hline Quadratic & 0.9999 & 0.9998 & 0.9996 & 0.58 & 0.27 & Suggested \\
\hline \multicolumn{7}{|c|}{ Response (Y2) } \\
\hline Linear & 0.6311 & 0.5460 & 0.2563 & 2.69 & - & - \\
\hline $2 \mathrm{FI}$ & 0.6774 & 0.4839 & -0.5391 & 2.86 & - & - \\
\hline Quadratic & 0.9889 & 0.9746 & 0.9716 & 0.63 & 0.95 & Suggested \\
\hline \multicolumn{7}{|c|}{ Response (Y3) } \\
\hline Linear & 0.9305 & 0.9145 & 0.8583 & 1.05 & - & - \\
\hline $2 \mathrm{FI}$ & 0.9340 & 0.8944 & 0.6764 & 1.16 & - & - \\
\hline Quadratic & 0.9976 & 0.9945 & 0.9709 & 0.26 & 1.41 & Suggested \\
\hline
\end{tabular}

Table 4: Summary of results of regression analysis for response $\mathrm{Y} 1$, $\mathrm{Y} 2$, and $\mathrm{Y} 3$.

\begin{tabular}{|c|c|c|c|}
\hline $\begin{array}{l}\text { Result of the analysis of } \\
\text { variance }\end{array}$ & $\begin{array}{l}\text { Particle size } \\
\text { (nm) (Y1) }\end{array}$ & $\begin{array}{c}\text { Entrapment } \\
\text { efficiency }(\%)(Y 2)\end{array}$ & $\begin{array}{l}\text { Drug loading } \\
\text { (\%) (Y3) }\end{array}$ \\
\hline \multicolumn{4}{|l|}{ Regression } \\
\hline Some of square & 22286.24 & 251.37 & 204.42 \\
\hline Degrees of freedom (df) & 9 & 9 & 9 \\
\hline Mean squares & 2476.25 & 27.93 & 22.71 \\
\hline F-value & 7288.58 & 69.33 & 323.46 \\
\hline $\mathrm{P}$ & $<0.0001$ & $<0.0001$ & $<0.0001$ \\
\hline Inference & Significant & Significant & Significant \\
\hline \multicolumn{4}{|l|}{ Lack of fit tests } \\
\hline Some of square & 0.37 & 0.20 & 0.36 \\
\hline Degrees of freedom (df) & 3 & 3 & 3 \\
\hline Mean squares & 0.12 & 0.065 & 0.12 \\
\hline F-value & 0.24 & 0.099 & 3.64 \\
\hline$P$ & 0.8618 & 0.9563 & 0.1221 \\
\hline Inference & $\begin{array}{l}\text { Non- } \\
\text { Significant }\end{array}$ & Non- Significant & Non-Significant \\
\hline $\mathrm{R}^{2}$ & 0.9999 & 0.9889 & 0.9976 \\
\hline $\begin{array}{l}\text { Correlation of variation } \\
(\% \mathrm{CV})\end{array}$ & 0.27 & 0.95 & 1.41 \\
\hline \multicolumn{4}{|l|}{ Residual } \\
\hline Some of square & 2.38 & 2.82 & 0.49 \\
\hline Degrees of freedom (df) & 7 & 7 & 7 \\
\hline Mean squares & 0.34 & 0.40 & 0.070 \\
\hline Standard deviation (SD) & 0.58 & 0.63 & 0.26 \\
\hline
\end{tabular}

Table 5: Analysis of variance of calculated model for response $\mathrm{Y} 1, \mathrm{Y} 2$ and $\mathrm{Y} 3$.

$$
\mathrm{Y} 1=+194.83+12.95 \mathrm{~A}-28.36 \mathrm{~B}-25.48 \mathrm{C}+2.25 \mathrm{AB}+17.73 \mathrm{AC}-
$$$$
3.86 \mathrm{BC}-10.47 \mathrm{~A}^{2}+37.77 \mathrm{~B}^{2}+18.20 \mathrm{C}^{2}
$$

The model F-value of 7288.58 implied that the model was significant $(\mathrm{p}<0.0001)$. The 'Lack of Fit F-value' of 0.24 implied that the Lack of Fit was not significant $(\mathrm{p}=0.8618)$.

In this case $\mathrm{A}, \mathrm{B}, \mathrm{C}, \mathrm{AB}, \mathrm{BC}, \mathrm{AC}, \mathrm{A}^{2}, \mathrm{~B}^{2}$ and $\mathrm{C}^{2}$ were significant model terms. Positive coefficients of $\mathrm{A}, \mathrm{AB}, \mathrm{AC}, \mathrm{B}^{2}$ and $\mathrm{C}^{2}$ in equation (5) indicated the synergistic effect on particle size while negative coefficients of $\mathrm{B}, \mathrm{C}, \mathrm{BC}$ and $\mathrm{A}^{2}$ indicated the antagonistic effect on particle size. The "Pred R Squared" of 0.9996 was in reasonable agreement with the "Adj $\mathrm{R}$ - Squared" of 0.9998 , indicating the adequacy of the model to predict the response of particle size.

The 'Adeq Precision' of 345.975 indicated an adequate signal. Therefore, this model was used to navigate the design space. The contour plots for particle size are shown in Figures 1a-1c. Table 6 demonstrates the actual and predicted value of particle size (Figure 1d).
An increase in particle size from $239.76 \mathrm{~nm}(\mathrm{H} 1)$ to $260.65 \mathrm{~nm}(\mathrm{H} 2)$ was observed on increasing the drug to lipid ratio from 1:2 to 1:4 (Table 6). This was probably caused by the aggregation of particles because of the concentration of surfactant was constant and not enough to form a proctitive layer on each particle. A decrease in particle size from 193.98 $\mathrm{nm}$ (H13) to172.9 nm (H12) was observed on increasing surfactant concetration (up to certain limit) and stirring speed. The probale mechanism of this behaviour could be that as the particle size decrease on increasing stirring speed, the surface area increase. For stabilization of SLNs, the surfactant forms a coating layer so that lipid nanoparticles do not coalesce.

\section{Effect of independent factors on \% entrapment efficiency}

The second-order polynomial equation (6) relating the response of $\%$ entrapment efficiency (Y2) is given below:

$$
\begin{aligned}
& \mathrm{Y} 2=+67.81+2.84 \mathrm{~A}-0.71 \mathrm{~B}-3.39 \mathrm{C}-0.78 \mathrm{AB}+0.69 \mathrm{AC}-1.36 \mathrm{BC} \\
&+1.74 \mathrm{~A}^{2}-4.06 \mathrm{~B}^{2}+0.22 \mathrm{C}^{2}
\end{aligned}
$$

The model F- value of 69.33 implied that the model was significant $(p<0.0001)$. The 'Lack of Fit F- value' of 0.099 implied that the Lack of Fit was not significant $(p=0.9563)$. In this case $A, B, C, A B, B C, A^{2}$ and $B^{2}$ were significant model terms. Positive coefficients of $A, A C, A^{2}$ and $\mathrm{C}^{2}$ in equation (6) indicated the synergistic effect on $\%$ entrapment efficiency, while negative coefficients of $B, C, A B, B C$, and $B^{2}$ indicated the antagonistic effect on \% entrapment efficiency. The "Pred R Squared" of 0.9716 was in reasonable agreement with the "Adj R - Squared" of 0.9746 , indicating the adequacy of the model to predict the response of entrapment efficiency. The 'Adeq Precision' of 34.30 indicated an adequate signal. Therefore, this model was used to navigate the design space. The contour plots for \% entrapment efficiency are shown in Figures $2 \mathrm{a}-2 \mathrm{c}$. Table 7 demonstrates the actual and predicted value of entrapment efficiency (Figure 2d). The effect of drug to lipid ratio on $\%$ entrapment efficiency depends on the extent of drug solubility in lipid. An increase in \% entrapment efficiency from $62.76(\mathrm{H} 1)$ to $69.87(\mathrm{H} 2)$ was observed on increasing the drug lipid ratio from 1:2 to 1:4 (Table 7). This is due to large amount of lipid present for drug entrapment On further increasing the drug to lipid ratio the entrapment efficiency was decreased. This is due to expulsion of drug from particle surface [18]. A decrease in \% entrapment efficiency from 69.00 (H13) to 65.32 (H12) was observed on increasing surfactant concetration and stirring speed. This shows that the excess quantity of emulsifier formed micellar solution which increases the solubility of haloperidol in the aqueous phase rather than the lipid phase. Therefore, the drug could partition 
Citation: Yasir M, Sara UVS, Som I (2015) Haloperidol Loaded Solid Lipid Nanoparticles for Nose to Brain Delivery: Stability and In vivo Studies. J Nanomedic Nanotechnol S7:006. doi:10.4172/2157-7439.S7-006

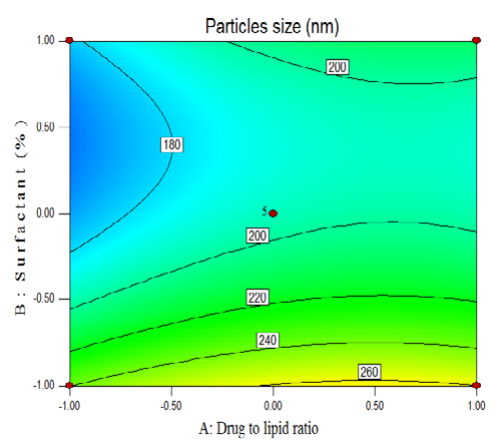

(a)

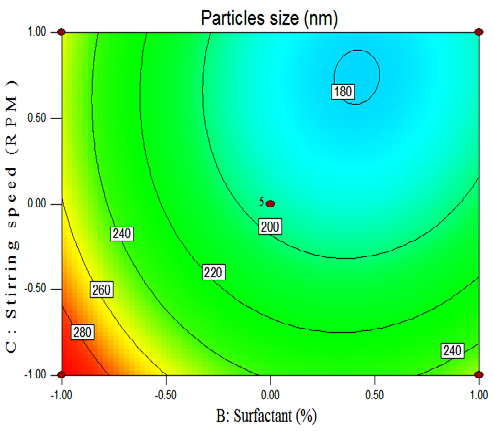

(c)

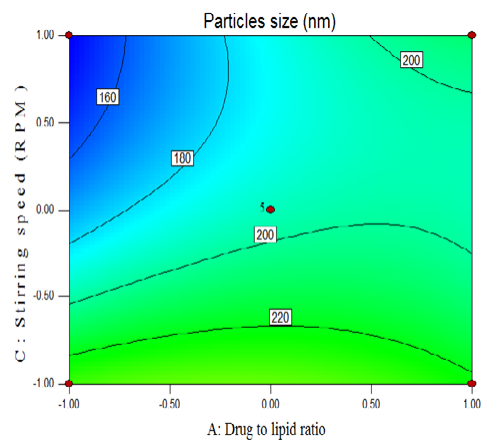

(b)

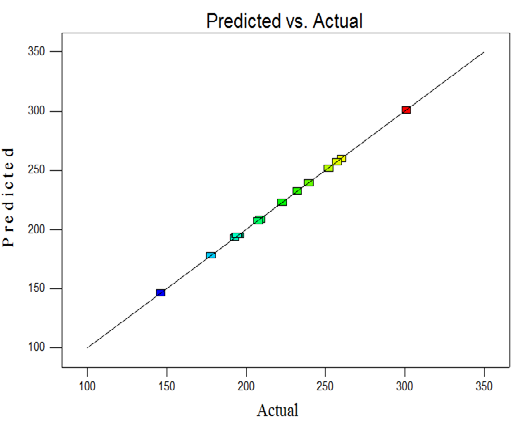

(d)

Figure 1: (a-c) Contour plots showing relative effects of different process parameters on particle size (d) plot of predicted vs. actual values for particle size.

\begin{tabular}{|c|c|c|c|}
\hline \multirow{2}{*}{$\begin{array}{l}\text { Formulation } \\
\text { code }\end{array}$} & \multicolumn{3}{|c|}{ Particle size $(\mathrm{nm})$} \\
\hline & Actual value & Predicted value & Residual value \\
\hline $\mathrm{H} 1$ & 239.76 & 237.93 & 1.83 \\
\hline $\mathrm{H} 2$ & 260.65 & 258.62 & 2.03 \\
\hline $\mathrm{H} 3$ & 177.97 & 180.00 & -2.03 \\
\hline $\mathrm{H} 4$ & 208.95 & 209.63 & -0.68 \\
\hline H5 & 232.32 & 230.52 & 1.8 \\
\hline $\mathrm{H} 6$ & 222.74 & 224.97 & -2.23 \\
\hline $\mathrm{H} 7$ & 146.34 & 146.11 & 0.23 \\
\hline $\mathrm{H} 8$ & 207.67 & 208.47 & -1.2 \\
\hline H9 & 300.98 & 298.78 & 2.2 \\
\hline $\mathrm{H} 10$ & 252.12 & 251.78 & 1.34 \\
\hline $\mathrm{H} 11$ & 257.32 & 257.55 & -0.23 \\
\hline $\mathrm{H} 12$ & 172.90 & 173.10 & -0.2 \\
\hline $\mathrm{H} 13$ & 193.98 & 193.83 & 0.17 \\
\hline $\mathrm{H} 14$ & 195.87 & 193.83 & 2.04 \\
\hline $\mathrm{H} 15$ & 195.87 & 193.83 & 2.04 \\
\hline $\mathrm{H} 16$ & 194.67 & 193.83 & 0.84 \\
\hline $\mathrm{H} 17$ & 194.67 & 193.83 & 0.84 \\
\hline
\end{tabular}

Table 6: Actual and predicted values for particle size.

from SLNs into the formed micelles in the water phase during stirring or washing time [19].

\section{Effect of independent factors on \% drug loading}

The second - order polynomial equation (7) relating the response of $\%$ drug loading (Y3) is given below:

$\mathrm{Y} 3=+18.43-4.83 \mathrm{~A}-0.16 \mathrm{~B}+0.68 \mathrm{C}-0.14 \mathrm{AB}-0.21 \mathrm{AC}-0.34 \mathrm{BC}+$ $1.6 \mathrm{~A}^{2}-0.81 \mathrm{~B}^{2}-0.019 \mathrm{C}^{2}$

\begin{tabular}{|c|c|c|c|}
\hline \multirow{2}{*}{$\begin{array}{c}\text { Formulation } \\
\text { code }\end{array}$} & \multicolumn{3}{|c|}{ Entrapment efficiency (\%) } \\
\hline H1 & Actual value & Predicted value & Residual value \\
\hline H2 & 62.76 & 62.58 & 0.18 \\
\hline H3 & 69.87 & 65.82 & 1.05 \\
\hline H4 & 66.67 & 63.22 & -0.55 \\
\hline H5 & 64.08 & 66.84 & -0.18 \\
\hline H6 & 68.50 & 64.23 & -0.15 \\
\hline H7 & 69.65 & 69.12 & -0.62 \\
\hline H8 & 76.83 & 69.23 & 0.42 \\
\hline H9 & 59.89 & 76.68 & 0.15 \\
\hline H10 & 61.43 & 58.92 & 0.97 \\
\hline H11 & 69.23 & 61.23 & 0.20 \\
\hline H12 & 65.32 & 69.43 & -0.20 \\
\hline H13 & 69.00 & 66.29 & 1.03 \\
\hline H14 & 67.90 & 67.81 & 1.19 \\
\hline H15 & 66.90 & 67.81 & 0.10 \\
\hline H16 & 67.23 & 67.81 & -0.91 \\
\hline H17 & 68.00 & 67.81 & -0.58 \\
\hline
\end{tabular}

Table 7: Actual and predicted values for \% entrapment efficiency.

The model F - value of 323.46 implied that the model was significant $(\mathrm{p}<0.0001)$. The 'Lack of Fit F-value 'of 3.64 implied that the Lack of Fit was not significant $(\mathrm{p}=0.1221)$.

In this case $\mathrm{A}, \mathrm{C}, \mathrm{AB}, \mathrm{BC}, \mathrm{A}^{2}$ and $\mathrm{B}^{2}$ were significant model terms. Positive coefficients of $C$ and $A^{2}$ in equation (7) indicated the synergistic effect on \% drug loading, while negative coefficients of $A, B, A B, B C$, $A C, B^{2}$ and $C^{2}$ indicated the antagonistic effect on $\%$ drug loading.

The "Pred R Squared" of 0.9709 was in reasonable agreement 
Citation: Yasir M, Sara UVS, Som I (2015) Haloperidol Loaded Solid Lipid Nanoparticles for Nose to Brain Delivery: Stability and In vivo Studies. J Nanomedic Nanotechnol S7:006. doi:10.4172/2157-7439.S7-006

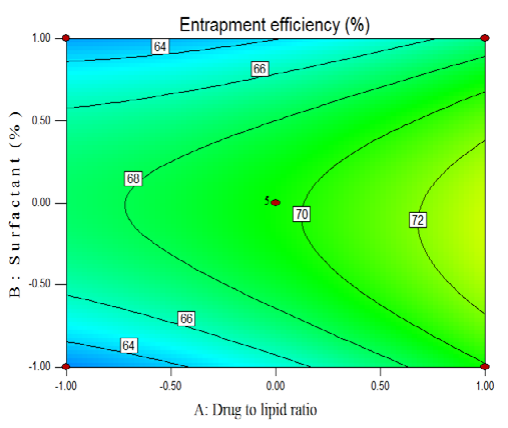

(a)

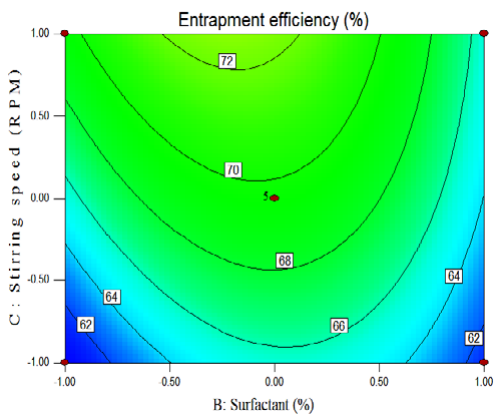

(c)

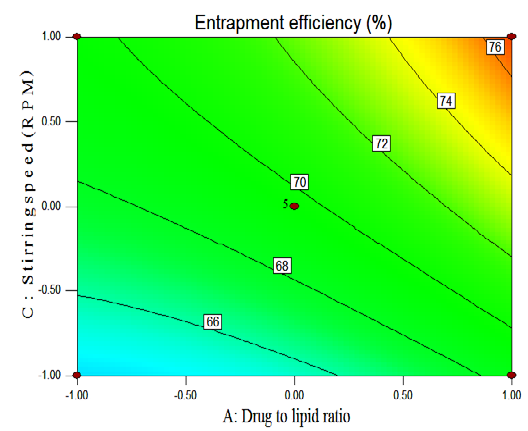

(b)

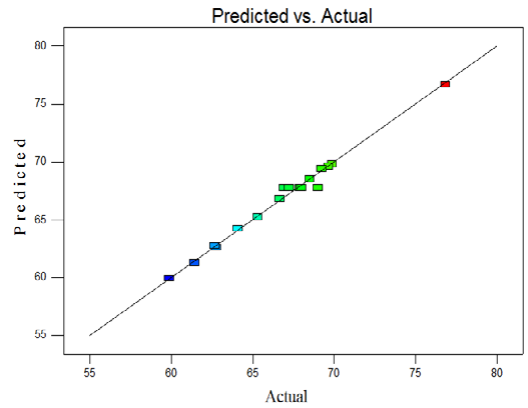

(d)

Figure 2: (a-c) Contour plots showing relative effects of different process parameters on percent entrapment efficiency (d) plot of predicted vs. actual values for entrapment efficiency.

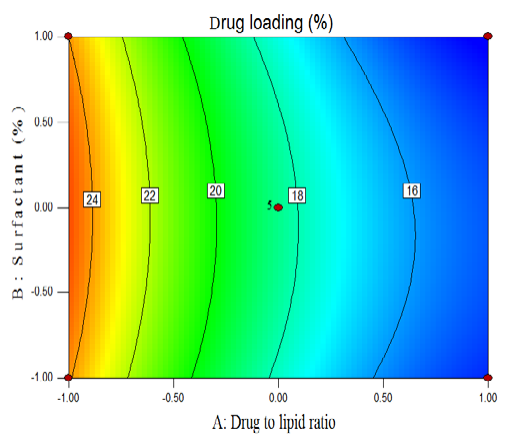

(a)

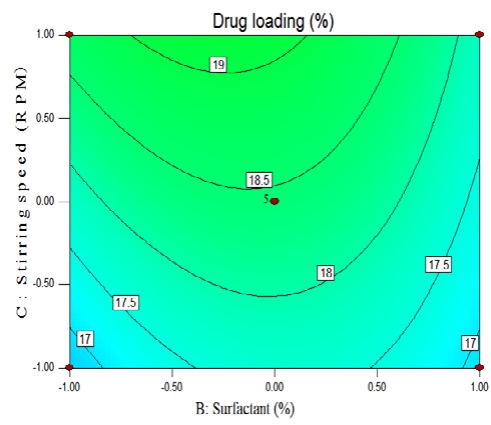

(c)

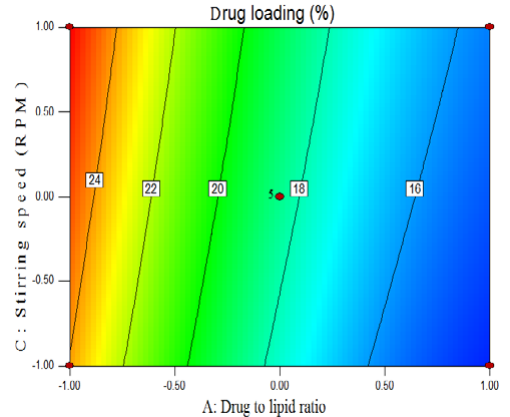

(b)

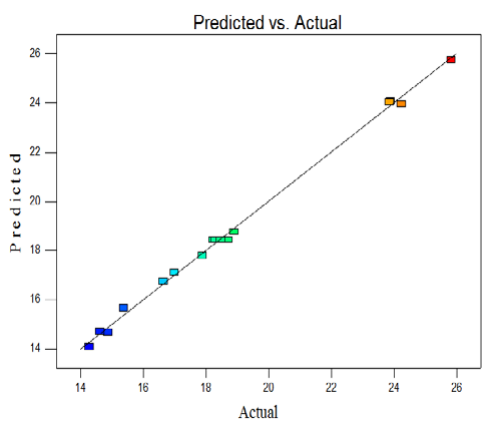

(d)

Figure 3: (a-c) Contour plots showing relative effects of different process parameters on percent drug loading (d) plot of predicted vs. actual values for drug loading. 
Citation: Yasir M, Sara UVS, Som I (2015) Haloperidol Loaded Solid Lipid Nanoparticles for Nose to Brain Delivery: Stability and In vivo Studies. J Nanomedic Nanotechnol S7:006. doi:10.4172/2157-7439.S7-006

Page 7 of 9

with the "Adj R - Squared" of 0.9945 , indicating the adequacy of the model to predict the response of drug loading. The 'Adeq Precision' of 57.304 indicated an adequate signal. Therefore, this model was used to navigate the design space. The contour plots for $\%$ drug loading are shown in Figures 3a-3c.

Table 8 demonstrates the actual and predicted value of drug loading (Figure 3d). The effect of drug to lipid ratio on \% drug loading is concentration dependent. A decrease in \% drug loading from 25.82 (H7) to $16.11(\mathrm{H} 8)$ was observed on increasing the drug to lipid ratio from 1:2 to 1:4 (Table 8) while stirring speed also have positive effect on $\%$ drug loading.

\section{Optimization of data and validation of response surface methodology}

Four formulations of SLN (H7, OH1, OH2, OH3) were selected from point prediction software of design expert and their responses i.e. particle size, entrapment efficiency and drug loading were evaluated. The composition of all optimum check point formulations, their actual and predicted values for the responses and the \% prediction error are shown in Table 9. The low value of \% prediction error assures the validity of generated equations and thus depicts the domain of

\begin{tabular}{|c|c|c|c|}
\hline \multirow{2}{*}{$\begin{array}{l}\text { Formulation } \\
\text { code }\end{array}$} & \multicolumn{3}{|c|}{ Drug loading (\%) } \\
\hline & Actual value & Predicted value & Residual value \\
\hline $\mathrm{H} 1$ & 23.88 & 24.07 & -0.19 \\
\hline $\mathrm{H} 2$ & 14.87 & 14.69 & 0.18 \\
\hline $\mathrm{H} 3$ & 23.85 & 24.03 & -0.18 \\
\hline $\mathrm{H} 4$ & 14.28 & 14.09 & 0.19 \\
\hline H5 & 24.24 & 23.95 & 0.29 \\
\hline $\mathrm{H} 6$ & 14.62 & 14.70 & -0.085 \\
\hline $\mathrm{H} 7$ & 25.82 & 25.73 & 0.085 \\
\hline $\mathrm{H} 8$ & 16.11 & 15.66 & 0.44 \\
\hline $\mathrm{H} 9$ & 16.64 & 16.74 & -0.096 \\
\hline $\mathrm{H} 10$ & 16.99 & 17.10 & 0.11 \\
\hline $\mathrm{H} 11$ & 18.89 & 18.78 & -0.11 \\
\hline $\mathrm{H} 12$ & 17.88 & 16.78 & 1.10 \\
\hline $\mathrm{H} 13$ & 18.87 & 17.43 & 1.44 \\
\hline $\mathrm{H} 14$ & 18.45 & 17.43 & 1.02 \\
\hline $\mathrm{H} 15$ & 18.23 & 17.43 & 0.80 \\
\hline $\mathrm{H} 16$ & 18.30 & 17.43 & 0.87 \\
\hline $\mathrm{H} 17$ & 18.47 & 17.43 & 1.04 \\
\hline
\end{tabular}

Table 8: Actual and predicted values for $\%$ drug loading.

\begin{tabular}{|c|c|c|c|c|c|}
\hline FC & Composition & Response & Actual value* & Predicted value* & \% Error \\
\hline \multirow[t]{3}{*}{$\mathrm{H} 7$} & $-1: 00: 1$ & $\mathrm{Y} 1$ & $146.34 \pm 3.59$ & $148.17 \pm 2.35$ & -1.25 \\
\hline & & Y2 & $69.65 \pm 0.89$ & $69.10 \pm 2.45$ & 0.79 \\
\hline & & Y3 & $25.82 \pm 2.45$ & $25.68 \pm 0.95$ & 0.54 \\
\hline \multirow[t]{3}{*}{$\mathrm{OH} 1$} & $-0.75: 00: 1$ & Y1 & $156.77 \pm 3.95$ & $158.12 \pm 4.67$ & -0.86 \\
\hline & & Y2 & $68.35 \pm 2.67$ & $70.13 \pm 1.89$ & -2.6 \\
\hline & & Y3 & $23.47 \pm 0.57$ & $23.85 \pm 1.32$ & -1.62 \\
\hline \multirow[t]{3}{*}{$\mathrm{OH} 2$} & $-0.75: 0.25: 1$ & Y1 & $150.25 \pm 5.76$ & $153.05 \pm 3.98$ & -1.86 \\
\hline & & Y2 & $70.43 \pm 2.56$ & $69.41 \pm 1.02$ & 1.45 \\
\hline & & Y3 & $23.97 \pm 0.95$ & $23.48 \pm 0.88$ & 2.04 \\
\hline \multirow[t]{3}{*}{$\mathrm{OH} 3$} & $-1: 0.25: 1$ & Y1 & $140.49 \pm 2.97$ & $138.36 \pm 5.21$ & 1.51 \\
\hline & & Y2 & $70.65 \pm 1.78$ & $69.01 \pm 1.34$ & 2.32 \\
\hline & & Y3 & $26.01 \pm 1.23$ & $25.65 \pm 1.2$ & 1.38 \\
\hline
\end{tabular}

applicability of response surface methodology (RSM) model. Finally, the optimum values of different variables i.e. drug to lipid ratio (1:2), surfactant concentration $(1.625 \% \mathrm{w} / \mathrm{v})$ and stirring speed $(3000 \mathrm{rpm})$ were obtained $(\mathrm{OH} 3)$.

The formulation $(\mathrm{OH} 3)$ optimized here showed an average particle size of $140.49 \pm 2.97 \mathrm{~nm}$, entrapment efficiency of $70.65 \pm 1.78 \%$ and drug loading of $26.01 \pm 1.23 \%$. This result showed $101.54 \%, 102.38 \%$ and $101.41 \%$ validity of the predicted values of predicted responses.

The optimized formulation $(\mathrm{OH} 3)$ was further optimized by varying stirring time from $2 \mathrm{~h}$ to $2.5 \mathrm{~h}$ while maintaining all factors constant. A further decrease in particle size from $140.49 \mathrm{~nm}(\mathrm{OH} 3)$ to $115.1 \mathrm{~nm}$ $(\mathrm{OPH})$ was observed on increasing the stirring time from 2 to $2.5 \mathrm{~h}$ while $\%$ drug entrapment and \% drug loading were not significantly affected. Finally formulation OPH (Table 5) was considered as optimized formulation. The optimum values of different variables i.e. drug to lipid ratio (1:2), surfactant concentration $(1.625 \% \mathrm{w} / \mathrm{v})$, stirring speed $(3000 \mathrm{rpm})$ and stirring time $(2.5 \mathrm{~h})$ were obtained $(\mathrm{OPH})$. The Optimized formulation (OPH) showed an average of particle size of $115.1 \pm 2.78 \mathrm{~nm}$, entrapment efficiency of $71.56 \pm 0.1 .56 \%$ and drug loading of $26.35 \pm 0.56 \%$. The optimized formation (OPH) was used for stability and in vivo study.

\section{Stability studies}

The stability of SLN formulation on storage is of great concern, as it is the major hindrance to the development of the marketed preparations. Aggregation and fusion, which lead to change in particle size distribution, are the main factors resulting in the physical instability of the system. The effect produced by these instabilities can influence the in vivo behaviour of the solid lipid nanoparticles. Therefore, extensive studies are required before a lipid based formulation is used for pharmacological therapy. The physical stability of the developed optimized HP - SLN formulation was evaluated following storage at 4 $\pm 2^{\circ} \mathrm{C}, 25 \pm 2^{\circ} \mathrm{C} / 60 \pm 5 \% \mathrm{RH}$ and $40 \pm 2^{\circ} \mathrm{C} / 75 \pm 5 \% \mathrm{RH}$ for the various length of time, and effect was observed on particle size, zeta potential, entrapment efficiency and drug loading.

\section{Effect of storage condition on particle size, zeta potential,} entrapment efficiency (\%) and drug loading (\%)

No significant $(\mathrm{P}<0.05)$ change was observed in particle size of HP-SLN formulations when they were stored at $4 \pm 2^{\circ} \mathrm{C}$ (refrigerator) and $25 \pm 2^{\circ} \mathrm{C} / 60 \pm 5 \% \mathrm{RH}$ up to six month, but the size of particles increased significantly $(\mathrm{P}<0.001)$ when they were stored at $40 \pm 2^{\circ} \mathrm{C} / 75$ $\pm 5 \% \mathrm{RH}$ due to aggregation. These results indicated that aggregation

\footnotetext{
$\begin{aligned} * \text { Values are mean } \pm \text { SD, } n=3, \text { FC } & =\text { Formulation code } \\ & \text { Table 9: Point prediction check point for optimization, actual values, experimental values and } \% \text { error. }\end{aligned}$

$\begin{aligned} * \text { Values are mean } \pm \mathrm{SD}, \mathrm{n}=3, \mathrm{FC} & =\text { Formulation code } \\ & \text { Table 9: Point prediction check point for optimization, actual values, experimental values and } \% \text { error }\end{aligned}$
} 
Citation: Yasir M, Sara UVS, Som I (2015) Haloperidol Loaded Solid Lipid Nanoparticles for Nose to Brain Delivery: Stability and In vivo Studies. J Nanomedic Nanotechnol S7:006. doi:10.4172/2157-7439.S7-006

Page 8 of 9

was temperature dependent (Figure 4a). The phenomenon of SLNs aggregation was further conformed by TEM image of optimized HPSLNs formulation $(\mathrm{OPH})$ after 6 month storage at $40 \pm 2^{\circ} \mathrm{C} / 75 \pm 5 \%$ $\mathrm{RH}$.

Zeta potential plays an important role in physical stability. There was no significant $(\mathrm{P}<0.05)$ change observed in zeta potential of SLN formulation $(\mathrm{OPH})$ when they were stored at $4 \pm 2^{\circ} \mathrm{C}$ (refrigerator) and $25 \pm 2^{\circ} \mathrm{C} / 60 \pm 5 \% \mathrm{RH}$ up to six month but a significant dropped in zeta potential at $40 \pm 2^{\circ} \mathrm{C} / 75 \pm 5 \% \mathrm{RH}(\mathrm{P}<0.001)$ up to 3 month were found. This might be due to the fact that at a high temperature and relative humidity, the outer surfactant coating dissolved out leading to aggregation of nanoparticles (Figure $4 \mathrm{~b}$ ).

There was no significant $(\mathrm{P}<0.05)$ difference observed on entrapment efficiency (\%) and drug loading (\%) as shown in Figures $4 \mathrm{c}$ and $4 \mathrm{~d}$ respectively.

\section{In vivo studies for the determination of pharmacokinetic and brain targeting parameters}

Various pharmacokinetic parameters of haloperidol were determined as shown in Table 10. The lower value of $\mathrm{T}_{\max }$ for brain (2 $\mathrm{h}$ ) as compared to blood ( $4 \mathrm{~h}$ ) may attribute to the preferential nose to brain transport following i.n. administration. The value of $\mathrm{C}_{\max }(329.17$ $\pm 20.89 \mathrm{ng} / \mathrm{mL}$ ) for brain after intranasal administration of HP-SLNs was significantly $(\mathrm{P}<0.05)$ higher than HP Sol administered intranasally and intravenously. Similarly, the value of $\mathrm{AUC}_{0-\infty}(2389.17 \pm 78.82$ ng.h/mL) of HP-SLNs i.n. was found to be significantly $(\mathrm{P}<0.05)$ higher than HP-Sol (i.n. and i.v.). This might be due to the direct transport of drug through olfactory route by bypassing the BBB.

As reported by Dhuria and co-workers [20], the drug uptake by brain from the nasal mucosa can be achieved via three major pathways (i) a systemic pathway of drug absorption into the blood circulation which subsequently reaches to the brain across the BBB, (ii) lymphatic pathway [16] (iii) a direct pathway from nasal mucosa epithelium into brain mainly along olfactory or trigeminal nerves by passing the $\mathrm{BBB}$ [21]. The extent of nose-to - brain delivery could be evaluated by the following parameters.

a) The brain/blood ratio, at $0.5 \mathrm{~h}$, following intranasal and intravenous administrations: This value was found to be1.61, 0.17 and

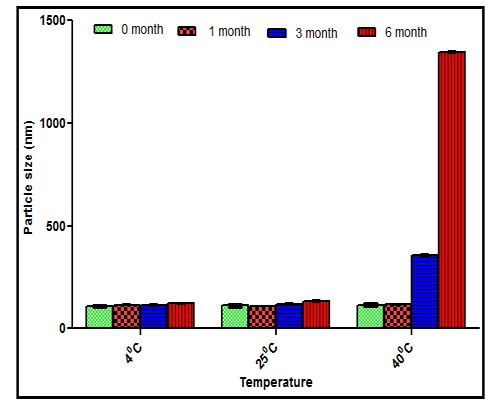

(a)

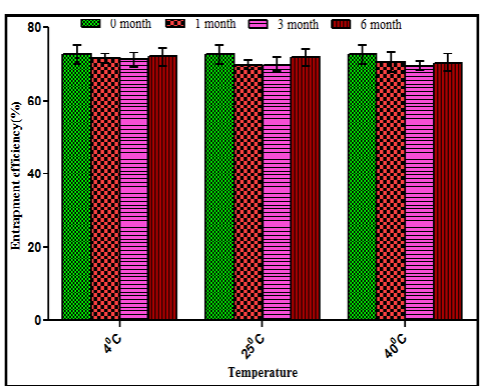

(c)

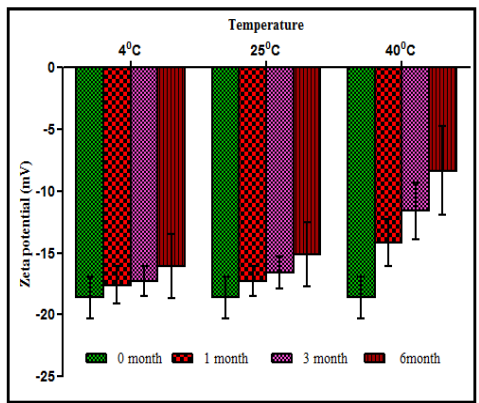

(b)

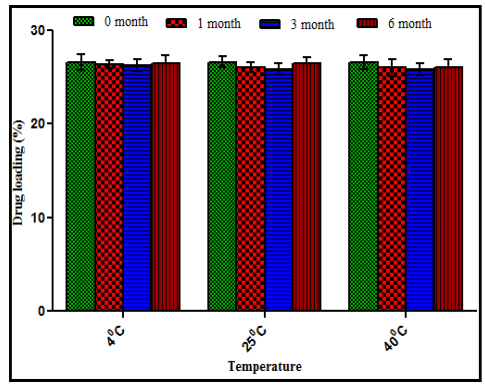

(d)

Figure 4: Effect of storage conditions on (a) particle size (b) zeta Potential (c) entrapment efficiency (d) drug loading of optimized formulation.

\begin{tabular}{|c|c|c|c|c|c|c|}
\hline \multirow[t]{3}{*}{ P, kinetic parameters } & \multicolumn{6}{|c|}{ Type of formulation/route of administration } \\
\hline & \multicolumn{2}{|c|}{ HP-SLN i.n.* } & \multicolumn{2}{|c|}{ HP-Sol. i.n." } & \multicolumn{2}{|c|}{ HP-Sol. i.v. } \\
\hline & Brain & Plasma & Brain & Plasma & Brain & Plasma \\
\hline$C_{\max }(\mathrm{ng} / \mathrm{mL})$ & $329.17 \pm 20.89$ & $393.5 \pm 24.63$ & $90.13 \pm 6.28$ & $306.96 \pm 13.47$ & $76.95 \pm 7.62$ & $2190 \pm 60.67$ \\
\hline$T_{\max }(\mathrm{h})$ & 2 & 4 & 2 & 1 & 1 & 0.167 \\
\hline$A U C_{0-24 h}(n g \cdot h / m L)$ & $2172.33 \pm 60.41$ & $2433.05 \pm 18.54$ & $623.16 \pm 8.51$ & $1460.71 \pm 15.67$ & $433.65 \pm 15.46$ & $11464.59 \pm 150.45$ \\
\hline$A U C_{0-\infty}(\mathbf{n g} \cdot \mathrm{h} / \mathrm{mL})$ & $2389.17 \pm 78.82$ & $2612.31 \pm 40.67$ & $683.15 \pm 30.17$ & $1681.82 \pm 32.83$ & $500.82 \pm 12.78$ & $12017.5 \pm 180.87$ \\
\hline$K_{\mathrm{e}}\left(\mathbf{h}^{-1}\right)$ & $0.079 \pm 0.0065$ & $0.097 \pm 0.003$ & $0.077 \pm 0.005$ & $0.11 \pm 0.003$ & $0.095 \pm 0.003$ & $0.15 \pm 0.007$ \\
\hline MRT (h) & $12.60 \pm 0.99$ & $7.60 \pm 0.32$ & $9.17 \pm 0.45$ & $8.9 \pm 0.57$ & $10.38 \pm 0.65$ & $5.92 \pm 0.57$ \\
\hline RB (\%) ${ }^{a}$ & $349.72 \pm 26.13$ & $155.32 \pm 11.83$ & & & & \\
\hline
\end{tabular}

Values are mean $\pm \mathrm{SD}, n=6$, a relative to HP sol. i.n., ${ }^{*} P<0.05$ versus HP sol. i.n., ${ }^{*} P<0.05$ versus HP sol. i.v., ${ }^{*} P<0.05$ versus HP sol. i.v., $P<0.05$ results are significant Table 10: Pharmacokinetic parameters of haloperidol in Brain and Plasma after HP-SLNs i.n., HP sol. i.n. and HP sol. i.v. administration to Rats. 
Citation: Yasir M, Sara UVS, Som I (2015) Haloperidol Loaded Solid Lipid Nanoparticles for Nose to Brain Delivery: Stability and In vivo Studies. J Nanomedic Nanotechnol S7:006. doi:10.4172/2157-7439.S7-006

0.03 for HP-SLNs i.n., HP-Sol i.n. and HP-Sol i.v. respectively. The significantly higher brain/blood ratio of HP-SLNs could indicate the brain targeting potential of developed SLNs. The HP-Sol also reached directly in brain to some extent but significantly less than HP SLNs. It might be due to lipophilic nature of haloperidol (log p approximately 4). Similar findings were observed by Kumar and co-workers [22].

b) Compared to HP-Sol administered intranasally, the percent relatively bioavailability of intranasal HP-SLNs, in blood and brain were $155.32 \pm 11.83$ and $349.72 \pm 26.13$ respectively. The results revealed a significant $(\mathrm{P}<0.05)$ enhancement in the bioavailability of haloperidol in the brain following the intranasal administration of HPSLNs. These findings are in line with Abdelbary and Tadros [16] who found that micellar nanocarriers increase the relatively bioavailability of olanzapine administered intranasally.

c) The DTI, DTE (\%) and DTP (\%) values were estimated to represent the percentage of drug directly transported to the brain via the olfactory or trigeminal pathway. The value of DTI, DTE and DTP for HP - SLNs administered intranasally was found to be 23.62 , $2362.43 \%$ and $95.77 \%$. While the value of DTI, DTE and DTP for HP-Sol administered intranasally was found to be $11.28,1128.61 \%$ and $91.14 \%$ respectively (Table 7 ). The DTI value $>1$ could confirm the direct pathway from nose to brain [17]. These findings are in line with Jain and co-workers [23], who found that micellar nanocarriers of zolmitriptan and coumarin increase the nose-to-brain uptake, via the olfactory region of the nasal cavity. Finally, it was concluded that the higher value of DTI, DTE (\%) and DTP (\%) suggest that HP - SLNs have better brain targeting potential as compared to HP-Sol administered intranasally. Similar findings have also been reported previously by Zhang and co-workers [24].

\section{Conclusion}

Finally, from the above findings, it could be concluded that the intranasal SLN formulations for haloperidol were developed and optimized by Box-Behnken design. Optimized formulation was subject to stability study and successfully delivered them into brain of rat. This provided a non-invasive route for efficient, rapid and direct nose to brain delivery of haloperidol. The intranasal delivery system is useful to avoid probable first pass metabolism and thus will reduce systemic side effects associated with drug and improve the bioavailability.

\section{Acknowledgements}

The author expresses deep appreciation and thanks to the management of ITS College of Pharmacy, Muradnagar, Ghaziabad, UP, India for their valuable cooperation in the present research work. Authors are also gratified to Vamsi labs Itd. Solapur, Maharashtra, India for providing the gift sample of haloperidol.

\section{References}

1. Vasir JK, Reddy MK, Labhasetwar VD (2004) Nanosystems in drug targeting: opportunities and challenges. Current Nanoscience1: 47-64.

2. Silva GA (2006) Neuroscience nanotechnology: progress, opportunities and challenges. Nat Rev Neurosci 7: 65-74.

3. Gastaldi L, Battaglia L, Peira E, Chirio D, Muntoni E, et al. (2014) Solid lipid nanoparticles as vehicles of drugs to the brain: current state of the art. Eur J Pharm Biopharm 87: 433-444.

4. Kaur IP, Bhandari R, Bhandari S, Kakkar V (2008) Potential of solid lipid nanoparticles in brain targeting. J Control Release 127: 97-109.

5. Blasi P, Giovagnoli S, Schoubben A, Ricci M, Rossi C (2007) Solid lipid nanoparticles for targeted brain drug delivery. Adv Drug Deliv Rev 59: 454-477.

6. Gajski G, Geric M, Garaj VV (2014) Evaluation of the in vitro cytogenotoxicity profile of antipsychotic drug haloperidol using human peripheral blood lymphocytes. Environmental Toxicology and Pharmacology 38: 316-324.
7. Yasir M, Sara UVS (2013) Preparation and optimization of haloperidol loaded solid lipid nanoparticles by Box-Behnken design. Journal of pharmacy research 7: 551-558.

8. Benvegnú DM, Barcelos RC, Boufleur N, Reckziegel P, Pase CS, et al. (2011) Haloperidol-loaded polysorbate-coated polymeric nanocapsules increase its efficacy in the antipsychotic treatment in rats. Eur J Pharm Biopharm 77: 332 336.

9. Yasir M, Sara UV (2014) Solid lipid nanoparticles for nose to brain delivery of haloperidol: in vitro drug release and pharmacokinetics evaluation. Acta Pharm Sin B 4: 454-463.

10. Hollister LE (1995) Basic and clinical Pharmacology. London: Prentice Hall.

11. Beresford R, Ward A (1987) Haloperidol decanoate. A preliminary review of its pharmacodynamic and pharmacokinetic properties and therapeutic use in psychosis. Drugs 33: 31-49.

12. Vaddi HK, Wang LZ, Ho PC, Chan SY (2001) Effect of some enhancers on the permeation of haloperidol through rat skin in vitro. Int J Pharm 212: 247-255.

13. Kumar R, Yasir M, Saraf SA, Gaur PK, Kumar Y, et al. (2013) Glyceryl monostearate based nanoparticles of mefenamic acid: fabrication and in vitro characterization. Drug Invention Today 5:246-250.

14. Varshosaz J, Tabbakhian M, Mohammadi MY (2010) Formulation and optimization of solid lipid nanoparticles of buspirone $\mathrm{HCl}$ for enhancement of its oral bioavailability. J Liposome Res 20: 286-296.

15. Maurya DP, Sultana Y, Aqil M, Kumar D, Chuttani K, et al. (2011) Formulation and optimization of alkaline extracted ispaghula husk microparticles of isoniazid - in vitro and in vivo assessment. J Microencapsul 28: 472-482.

16. Abdelbary GA, Tadros MI (2013) Brain targeting of olanzapine via intranasa delivery of core shell difunctional block copolymer mixed nanomicellar carriers: In vitro characterization, ex vivo estimation of nasal toxicity and in vivo biodistribution studies. International Journal of Pharmaceutics 452: 300-310.

17. Wang F, Jiang X, Lu W (2003) Profiles of methotrexate in blood and CSF following intranasal and intravenous administration to rats. Int J Pharm 263: 1-7.

18. Abdelbary G, Fahmy RH (2009) Diazepam-loaded solid lipid nanoparticles: design and characterization. AAPS PharmSciTech 10: 211-219.

19. Tiyaboonchai W, Tungpradit W, Plianbangchang P (2007) Formulation and characterization of curcuminoids loaded solid lipid nanoparticles. Int J Pharm 337: 299-306.

20. Dhuria SV, Hanson LR, Frey WH 2nd (2010) Intranasal delivery to the central nervous system: mechanisms and experimental considerations. J Pharm Sci 99: 1654-1673.

21. Md S, Khan RA, Mustafa G, Chuttani K, Baboota S, et al. (2013) Bromocriptine loaded chitosan nanoparticles intended for direct nose to brain delivery: pharmacodynamic, pharmacokinetic and scintigraphy study in mice model. Eur J Pharm Sci 48: 393-405.

22. Kumar M, Misra A, Mishra AK, Mishra P, Pathak K (2008) Mucoadhesive nanoemulsion-based intranasal drug delivery system of olanzapine for brain targeting. J Drug Target 16: 806-814.

23. Jain R, Nabar S, Dandekar P, Patravale V (2010) Micellar nanocarriers: potential nose-to-brain delivery of zolmitriptan as novel migraine therapy. Pharm Res 27: 655-664.

24. Zhang Q, Jiang X, Jiang W, Lu W, Su L, et al. (2004) Preparation of nimodipineloaded microemulsion for intranasal delivery and evaluation on the targeting efficiency to the brain. Int J Pharm 275: 85-96. 